Revista IBERC
$\begin{aligned} & \text { v. 2, n. 2, p. 01-19, mai.-ago./2019 } \\ & \text { www.responsabilidadecivil.org }\end{aligned}$

\title{
INDENIZIBILIDADE DO DANO MORTE NO BRASIL: UMA PERSPECTIVA ACERCA DA DEFESA DA VIDA
}

\author{
INDEMNIFIBILITY OF DEATH DAMAGE IN BRAZIL: A PERSPECTIVE ABOUT THE DEFENSE \\ OF LIFE
}

Camilla de Araújo Cavalcanti ${ }^{1}$

RESUMO: Insurge-se a Responsabilidade Civil de novos desafios quanto ao seu sentido e alcance e o surgimento de novos danos está à frente de todas as nuances que precisam ser observadas. A violação da vida humana, no aspecto da sua existência, não é passível de receber da responsabilidade civil a função reparadora nem punitiva, no Brasil, como resultado de um dano injusto. O dano que provoca a morte de uma pessoa não recebe olhar atento da lei, nem da jurisprudência brasileira, e recebe pouca atenção da doutrina. O propósito que nos anima, se refere ao estudo da defesa da vida e, neste contexto, analisar o fundamento da sua possível, e necessária, proteção sob a perspectiva da Responsabilidade Civil. Dúvidas no sentido da configuração, in re ipsa, dos danos morais aos familiares da pessoa falecida não existem, uma vez que o Código Civil brasileiro é expresso nesta previsão. Porém, outros danos causados ao de cujos, mesmo antes e pelo seu decesso, é um fato ignorado e reticente no nosso ordenamento jurídico. A claras luzes, danos são provocados à vida da pessoa lesada e outros ordenamentos jurídicos estrangeiros são convocados para esclarecer que a indenizabilidade pelo dano morte per si é possível, tanto quanto os danos corporais

\begin{abstract}
Civil liability is instigated by new challenges as to its meaning and range, the occurrence of new damages is ahead of all the nuances that need to be observed. In Brazil, the human life's violation, in its existential aspect, is not liable to receive from civil responsibility the repair or punitive function because of unfair harm. The damage caused by a person's death does not receive watchful eye of the law neither from Brazilian jurisprudence, and receives very little attention from the doctrine. The purpose that animates us refers to the study of the defense of life and, in this context, the analysis of the foundation of its protection, if possible and necessary, under the perspective of Civil liability perspective. Do not exist doubts regarding the configuration, in re ipsa, of moral damages to the relatives of the deceased, since the Brazilian Civil Code is expressed in this prediction. However, other damages caused to de cujus, even before and due to your death is an ignored and reticent fact in our legal system. Clearly, damage are brought to the injured person's life, and other foreign legal systems clarify that indemnity for the death damage per si is possible as much as the damages caused by the conduct of those who hurt and also the damages suffered until the death.
\end{abstract}

\footnotetext{
${ }^{1}$ Doutoranda e Mestre em Direito pela Faculdade de Direito da Universidade de Coimbra, Portugal. Membro do IBERC; Membro do IBDFAM; Advogada; Professora Universitária. E-mail: camillacavalcantiadv@gmail.com. ORCID n. 8459533310409341.
} 


\section{Revista IBERC}

v. 2 , n. 2 , p. 01-19, mai.-ago./2019

www.responsabilidadecivil.org

provocados pela conduta do lesante e sofridos pelo lesado que sofre até o seu decesso. Postas estas questões, outros desafios surgem no longínquo horizonte deste estudo, a atuação da equidade e o preço arbitrado pela perda de uma vida humana.

Palavras-chave: Responsabilidade Civil. Dano morte. Indenizabilidade.
Based on these issues, other challenges arise in the far horizon of this study, the action of equity and the price arbitrated by the loss of a human life.

Keywords: Civil Liability. Damages in wrongful death. Indemnity.

SUMÁRIO: 1. Introdução. 2. A defesa da vida como fundamento do direito. 3. A lei e jurisprudência brasileira - a reparação dos danos físicos ao lesado e danos morais aos sobrevivos em caso de decesso. 4. A indenizabilidade do dano morte no brasil - um horizonte próximo. 5. Conclusão. 6. Referências.

\section{INTRODUÇÃO}

Desde os primórdios dos estudos de leis incipientes, a exemplo do legado que nos deixou os estudos romanos a este respeito, em dar a cada um o que é seu, não ofender ninguém e viver honestamente, reside a figura do que se desenvolveria no instituto da responsabilidade civil.

Assiste-se, como causa inerente à convivência social, ao cometimento de danos, e se convoca a Responsabilização por danos, em suas funções preventiva, reparadora, sancionatória para atender ao lesado, uma vez um dano injusto a ele provocado.

O dano injusto que resulta no fim da vida de alguém, convoca o Estado enquanto ente de pacificação social, para punir, criminalmente, o agente provocador do ato ilícito e quanto a isto não são necessárias maiores divagações. O conflito posto diz respeito à aplicabilidade das funções da responsabilidade civil para o caso do dano morte, pois, sendo a vida um valor supremo a ser perseguido pelas comunidades internacionais, é dever do Estado considerar qualquer ofensa à sua proteção como um dano passível de indenização.

Não obstante, uma vez perquiridas as razões que autorizam a compensação pela espécie de dano morte, a exemplo do que acontece em Portugal e na Itália, outras questões são levantadas, como a legitimidade para recepção da compensação, se pelo de cujus e, posteriormente transferida aos seus sucessores uma vez inserta na sua esfera jurídica, ou se direito já dedicado à estas pessoas, por direito próprio.

As consequências da titularidade, de uma ou de outra forma, à recepção da compensação pelo dano morte, repercutiriam nas normas de direito sucessório, para o primeiro 


\section{Revista IBERC}

v. 2, n. 2, p. 01-19, mai.-ago./2019

www.responsabilidadecivil.org

caso, ou não, como uma relação obrigacional, excluídas as normas da transmissão hereditária, o que Ihe traz uma ampla diferença.

Depois, outra problemática se põe, mas, ressalte-se, não pela observância do dano morte, pois que a violação à vida é inconstitucional, mas em que pese no valor arbitrado a título de compensação pelo dano morte. Socorre-se, o legislador, para o caso da responsabilidade extracontratual, à equidade, todavia, valorar a vida humana pode dar margem à precificação da vida e da dor da saudade.

Para o caso brasileiro, não há qualquer desentendimento quanto aos danos morais suportados pelos familiares pela perda da vida de um ente querido. A indenização se dá diretamente às pessoas lesadas com o evento morte e que por isto, sofrem danos a sua integridade psíquica e também dessa forma se decide nos países europeus referidos.

Fala-se, também, de uma oura espécie de dano não verificada na lei brasileira, o dano de choque nervoso (Alemanha, o chamado Schockschaden, §823 do BGB) verificado naqueles que presenciam o evento morte e que, com isto, sofrem pelo que assistiu, desde que a vítima seja pessoa próxima, e haja efetivo dano psíquico, devidamente comprovado.

As nuances que envolvem o cometimento do dano morte são extensas e ignorá-las é fechar os olhos a uma realidade latente, sobretudo ao que corriqueiramente ocorre no Brasil. Postas estas razões a explicitação do tema é imperiosa com finalidade de tornar esta discussão pertinente sobretudo em razão da defesa da vida.

Passemos, portanto, a analisar, pari passu, acercada possibilidade da compensação da morte como dano ao lesado que perdera sua vida em detrimento de um ato de outrem e seus posteriores reflexos.

\section{A DEFESA DA VIDA COMO FUNDAMENTO DO DIREITO}

Testemunha-se a defesa do direito à vida como valor ético, de elevada estima moral e Cristã com referência expressa a sua proteção desde as cartas de direitos mais antigas, vale dizer, a Magna Carta de 1215, ainda na Idade Média, Petition of Rights, em 1628; Habeas Corpus Act, em 1679; o Bill of Rights, em 1689 e o Act of Settlement, em 1701; além da Carta de Direitos da Virgínia, de 1776, já no período moderno, todas elas com interesses de proteção da vida relativizados aos grupos sociais mais favorecidos, é verdade.

O surgimento da vida como valor inerente e fundamental à própria instituição do Estado, surgira após intensos estudos da teoria jusnaturalista, sobretudo a despeito de Locke, descrito por Bobbio, para quem o renascimento do jusnaturalismo se fez como surgimento da existência da

Revista IBERC, Minas Gerais, v. 2, n. 2, p. 01-19, mai.-ago./2019 


\section{Revista IBERC}

v. 2 , n. 2, p. 01-19, mai.-ago./2019

www.responsabilidadecivil.org

ideia de justiça, que transcende e induz a uma releitura do direito positivo de frente para ele, com o fim de modificá-lo, aperfeiçoá-lo e adaptá-lo às novas necessidades e a novos valores ${ }^{2}$.

Isto em conta, os costumes, desde as sociedades greco-romanas, sempre determinantes do comportamento civilizado das pessoas, embasa a criação do direito escrito e já nos primeiros códigos civis, com influência e a despeito do que prelecionara a Carta de Declaração dos Direitos do Homem e do Cidadão ${ }^{3}$, até as Constituições posteriores, vida humana é percebida como valor intrínseco às funções do Estado, enquanto legitimador do resguardo dos direitos dos cidadãos.

Em uma primeira vista, opõem-se ao Estado, os direitos dos indivíduos, contra qualquer ato que ofenda seus direitos. Por via oposta, roga-se ao Ente estatal que atue na preservação dos interesses dos cidadãos com o fim de evitar, ou reprimir, quaisquer atos que atentem contra a dignidade do ser enquanto pessoa.

A vida, per si, é fundamento das Constituições democráticas. Para o caso brasileiro, assim como se repete em outros países, é fundamento da república, vedada a pena de morte salvo em caso de guerra declarada ${ }^{4}$.

Para os códigos civis, há, a perseguir o caminho constitucional, a defesa da vida por meio da previsão dos direitos de personalidade, vale dizer, da pessoa, direitos intrínsecos ao que a dignidade respeita. Aqui, designam-se forma de assegurar outras relações de direitos que dizem respeito à defesa da vida humana, como a honra, a privacidade, nome, enfim, construídos a partir da defesa da vida e fundamento do direito enquanto direito.

\footnotetext{
${ }^{2}$ BOBBIO, Norberto. Locke e o direito natural. Brasília: Editora UNB, 1997. p. 25.

${ }^{3}$ A Carta de Declaração de direitos do homem e do cidadão, em seu preâmbulo, ressalta: "[...]considerando que a ignorância, o esquecimento ou o desprezo dos direitos do homem são as únicas causas das desgraças públicas e da corrupção dos governos, resolveram expor, em uma declaração solene, os direitos naturais, inalienáveis e consagrados do homem, para que esta declaração, sempre presente em todos os Membros do corpo social, recorde-Ihes incessantemente os seus direitos e os seus deveres [...]." Disponível em: http://www.conseil-constitutionnel.fr/conseil-constitutionnel/root/bank_mm/portugais/constitution_portugais.pdf. Acesso em: 04 ago. 2018. Antes mesmo das Constituições democráticas, embora atentos ao massacre milhões de pessoas, incluídas neste número as 12 condenações à pena de morte dos detratores, Cfr. Judgment at Nuremberg - Fifty years ago the trial of Nazi war criminals ended: the world had witnessed the rule of law invoked to punish unspeakable atrocities. Disponível em: http://w3.salemstate.edu/ cmauriello/pdf_his102/nuremberg.pdf. Acesso em: 04 ago. 2018; FERRO, Ana Luiza Almeida. O Tribunal de Nuremberg: dos precedentes à confirmação de seus princípios. Belo Horizonte: Mandamentos, 2002.

${ }^{4}$ (...) XLVII - não haverá penas: a) de morte, salvo em caso de guerra declarada, nos termos do art. 84, XIX; (...)" Para o caso português, a Constituição da República a prioriza, no Título II, no qual esboçam-se os Direitos, Liberdades e Garantias, o direito à Vida, vinculado à proibição de penas de morte (art. $24^{\circ}$ ); diploma constitucional italiano não se refere ao termo "vida", mas tutela, no artigo $2^{\circ}$, princípios fundamentais, nos quais são garantidos os direitos invioláveis do homem, como o desenvolvimento da sua personalidade, somando-se a este dispositivo, a proibição da pena de morte, traduzida na preservação da vida, de acordo com o exposto no artigo 27 da Constituição deste país; A Lei Fundamental alemã, destinando-se à guarda dos direitos fundamentais, evidencia a proteção da vida como defesa de um direito inerente à liberdade $\left(n^{\circ} 2\right.$, artigo 2), para referir alguns exemplos.
} 


\section{Revista IBERC}

v. 2, n. 2, p. 01-19, mai.-ago./2019

www.responsabilidadecivil.org

Direito inato e indisponível, a vida, que fundamenta o direito de personalidade, é intransponível e personalíssima, confluindo para sua inviolabilidade, que se origina ainda na concepção do nascituro e se prolonga para além do seu termo, como similarmente ocorre quando da ofensa à honra de pessoas já falecida ${ }^{5}$.

Disto, se torna verossímil pensar que nasce, na esfera jurídica do ofendido, o direito a ser indenizado quando o bem supremo vida é violado, seja na forma da lesão corporal, ofensa à honra ou ao bom nome, integridade biopsíquica, ou quando violada sua vida em plenitude, levando o sujeito à morte.

A agressão à vida constitui um ato ilícito, pela proteção moral e jurídica que lhe é própria, a incitar a responsabilização do lesante em caso também de morte do lesado. Controvérsias se formulam em questões circunscritas ao chamado "Direito à morte", e neste novo direito, diametralmente oposto ao Direito à vida, viabilizaria seu fim em casos particulares como a problemática do aborto, permitido nos casos específicos previstos na lei, quando ameace a vida da parturiente, ou em casos de encefalopatia, além das outras questões atinentes à eutanásia e morte assistida.

Para o momento, nos ocuparemos exclusivamente ao tema sugerido. Sendo a dignidade humana substrato ético que regula a vida, a cessação do ciclo vital, embora natural, jamais pode ser abreviado por terceiros e, mesmo com estas nuances limitadoras ao pleno reconhecimento do direito à vida, não sobram resistências outras que impossibilitem/limitem a indenizabilidade do dano morte quando provocado por ato ilícito, imputável ao lesante, atendidos os demais pressupostos da responsabilidade civil.

Opiniões pela reparação, ou não, pela perda da vida por ato injusto do lesante sobram na doutrina portuguesa, onde o dano morte é previsto legalmente ${ }^{6}$. Todavia, o debate posto foi

\footnotetext{
${ }^{5}$ Carneiro da Frada sustenta que o próprio artigo 70, n¹ do Código Civil português, quando proclama que "a lei protege todos os indivíduos contra qualquer ofensa à sua personalidade física ou moral", possibilita à jurisprudência portuguesa a ampliar o rol de direitos da pessoa que podem e devem ser tutelados, adequando-se às novas demandas. Entendemos, para o caso do dano morte, possível e necessária observância de ofensa ao direito à vida como direito de personalidade, por ofensa à integridade física da pessoa de tal forma que abarca o fim da vida. Cfr. FRADA, Manuel A. Carneiro da. Nos 40 anos do Código Civil Português Tutela da Personalidade e dano Existencial. In: Themis Revista de Direito, Edição Especial. Ano: 2008 , p. 47-68. Pedro Pais de Vasconcelos assume importante posição quando afirma ser o direito à vida o mais importante dos direitos de personalidade, todavia reconhece dificuldades que podem ser impostas quando discutidas questões periféricas como o aborto. VASCONCELOS, Pedro Pais de. Direito de personalidade. Coimbra: Almedina, 2014. p. 68-70. DIAS, Álvaro. Direito do ser humano de não ser morto. In: Dano corporal quadro epistemológico e aspectos ressarcitórios. Coimbra: Almedina, 2004. p. 105.

${ }^{6} \mathrm{Na}$ esteira do entendimento da indenizabilidade do dano morte, Diogo Leite de Campos resume: "o dano da morte é um dano de caráter não patrimonial para o próprio; ao facto que deu origem à morte podem ser imputáveis outros danos patrimoniais e não patrimoniais, sofridos pelo falecido; sendo também imputáveis à morte danos para terceiros, de caráter patrimonial e não patrimonial; todos estes danos devem ser indenizados." CAMPOS, Diogo Leite de. Os danos causados pela morte e sua indenização. In: Comemorações dos 35 anos do Código Civil e dos 25 anos da Reforma de 1977. Vol III, Das Obrigações.
}

Revista IBERC, Minas Gerais, v. 2, n. 2, p. 01-19, mai.-ago./2019 


\title{
Revista IBERC
}

v. 2, n. 2, p. 01-19, mai.-ago./2019

www.responsabilidadecivil.org

encerrado conforme prevê o Código Civil português, na letra do artigo $496^{\circ}, n^{\circ} 2$, cuja transcrição

é válida:

\author{
Art. $496^{\circ}$ - Danos não patrimoniais - \\ [...] \\ 2. Por morte da vítima, o direito à indemnização por danos não patrimoniais \\ cabe, em conjunto, ao cônjuge não separado de pessoas e bens e aos filhos ou \\ outros descendentes; na falta destes aos pais ou outros ascendentes; e, por \\ último, aos irmãos ou sobrinhos que os representem.
}

Em 2014, a Itália reconhecera a configuração do dano morte e possibilidade de ressarcimento pelo ato injusto que põe em causa a vida de uma pessoa. $\mathrm{Na}$ decisão da Corte di Cassazione $\mathrm{n}^{\circ}$ 1361/2014, de 23 de Janeiro, fora reconhecida a indenizabilidade do dano morte como dano autônomo, adquirido o direito à indenização pelo lesado no momento do falecimento, transmissível, portanto, via sucessória ${ }^{7}$.

O direito alemão se limita em observar o dano de choque nervoso causado pelo evento morte quando alguém o assiste e, com isto, sofre danos psíquicos que devem ser devidamente comprovados por laudo médico. No Reino unido, é reconhecido o dano de luto, devido aos

Coimbra: Coimbra editora, 2007. p.133-137. Carlos Pamplona Corte-Real reflete que "mais vale indenizar (o morto) do que nada fazer, pois se se admite a indenização por danos não patrimoniais, $v . g$ ofensas corporais, por maioria de razão deveria ser juridicamente reconhecida a indemnizibilidade do dano morte. De outro modo, cometer-se-ia uma injustiça no plano civil, visto não se poder negar a existência de um dano privado." CORTE-REAL, Carlos Pamplona. Curso de Direito das Sucessões. Lisboa: Quid Juris, 2012. p. 48. Oliveira Ascensão considera que a compensação "NUNCA poderia funcionar como equivalente ou compensação para o lesado; por natureza, ele nunca poderia desfrutar desse bem. ASCENSÃO, José Oliveira. Direito civil Sucessões. $4^{a}$ ed. Coimbra: Coimbra editora, 1989. p. 50. Antunes Varela, afirma: "embora a obrigação de indemnizar assente sobre vários pressupostos, entre os quais figura, em regra, a prática do fato ilícito, não pode esquecer-se que a indemnização é, essencialmente, reparação de um dano (de terceiro). Se e enquanto não houver dano, embora haja fato ilícito, não há obrigação de indemnizar. No caso especial da lesão ou agressão mortal, a morte é um dano que, pela própria natureza das coisas, não se verifica já na esfera jurídica do seu titular. «É inadmissível, como justamente observa o Conselheiro Arala Chaves num dos votos de vencido, reconhecer o nascimento do direito com o facto jurídico de que deriva, para o pretenso titular, incapacidade para o adquirir»." VARELA, Antunes. Das obrigações em geral. Vol. I, 10ª ed. Rev. e Atual. Coimbra: Almedina, 2014. p. 611. Em sentido diverso, Menezes Cordeiro reconhece a morte como um dano indenizável, fundamentando seu posicionamento afirmando que "a morte de uma pessoa constitui um dano, uma vez que a vida é um bem juridicamente tutelado através do direito à vida; trata-se de um dano com aspectos morais e patrimoniais; além disso, é um dano infligido ao morto e, reflexamente, a certos elementos que o rodeiam, nos aludidos aspectos morais e patrimoniais; finalmente, o ressarcimento de que beneficie a vítima transmite-se, pela morte, aos seus sucessores." CORDEIRO, António Menezes. Tratado de Direito Civil português - Vol. II Direito das obrigações T. III. Gestão de negócios, Enriquecimento sem causa; Responsabilidade civil. Coimbra: Almedina, 2010. p. 518. Sustentando a indenizabilidade do dano morte, também cfr. TELES, Inocêncio Galvão. Direito das Sucessões, Noções fundamentais. $6^{a}$ ed. Coimbra: Coimbra Editora, 1996; BARBOSA, Mafalda Miranda, (Im)pertinência da autonomização dos danos puramente morais? Considerações a propósito dos danos morais reflexos. In: Cadernos de direito privado. Jan-Mar 2014, n 45, p. 3-18.

${ }^{7}$ Disponível em: http://www.neldiritto.it/appgiurisprudenza.asp?id=10380\#.WpdU3ejwblU. Acesso em: 28. Fev. 2018.

Revista IBERC, Minas Gerais, v. 2, n. 2, p. 01-19, mai.-ago./2019 


\title{
Revista IBERC
}

v. 2, n. 2, p. 01-19, mai.-ago./2019

www.responsabilidadecivil.org

familiares da vítima, assim como hoje se sucede no Brasil, conforme letra do artigo 948 do Código Civil.

Celeuma acerca da indenizabilidade pela perda da vida fora suprimida de Portugal com a redação da norma acima transcrita. É bem verdade que no Brasil não há qualquer referência legal acerca do dano morte como espécie de novo dano a ser ressarcido, todavia, instrumentos para sua apreciação existem, conforme passaremos a observar.

\section{A LEI E JURISPRUDÊNCIA BRASILEIRA - A REPARAÇÃO DOS DANOS FÍSICOS AO LESADO E DANOS MORAIS AOS SOBREVIVOS EM CASO DE DECESSO}

A letra dos artigos 948 a 951 do Código Civil brasileiro prevê as condições para o ressarcimento por danos causados à integridade psicofísica do lesado, nos seguintes termos:

\begin{abstract}
Art. 948. No caso de homicídio, a indenização consiste, sem excluir outras reparações:

I - no pagamento das despesas com o tratamento da vítima, seu funeral e o luto da família; II - na prestação de alimentos às pessoas a quem o morto os devia, levando-se em conta a duração provável da vida da vítima.

Art. 949. No caso de lesão ou outra ofensa à saúde, o ofensor indenizará o ofendido das despesas do tratamento e dos lucros cessantes até ao fim da convalescença, além de algum outro prejuízo que o ofendido prove haver sofrido. Art. 950. Se da ofensa resultar defeito pelo qual o ofendido não possa exercer o seu ofício ou profissão, ou se lhe diminua a capacidade de trabalho, a indenização, além das despesas do tratamento e lucros cessantes até ao fim da convalescença, incluirá pensão correspondente à importância do trabalho para que se inabilitou, ou da depreciação que ele sofreu.

Parágrafo único. O prejudicado, se preferir, poderá exigir que a indenização seja arbitrada e paga de uma só vez.

Art. 951. O disposto nos arts. 948, 949 e 950 aplica-se ainda no caso de indenização devida por aquele que, no exercício de atividade profissional, por negligência, imprudência ou imperícia, causar a morte do paciente, agravar-lhe o mal, causar-lhe lesão, ou inabilitá-lo para o trabalho.
\end{abstract}

Da norma posta, percebemos a previsão do ressarcimento por danos patrimoniais e não patrimoniais a serem respondidos pelo lesante causador da abreviação da vida de alguém. Restringe-se a indenização pelos danos mensuráveis, a saber, as despesas necessárias aos tratamentos que o lesado possa ter se submetido, até seu decesso, com o funeral, e o luto da família, entendido este último como os danos morais causados aos sobrevivos pela perda do seu familiar.

Revista IBERC, Minas Gerais, v. 2, n. 2, p. 01-19, mai.-ago./2019 


\section{Revista IBERC}

v. 2 , n. 2 , p. 01-19, mai.-ago./2019

www.responsabilidadecivil.org

Depois, já no inciso II do artigo 948 retro, é previsto o arbitramento de pensão alimentícia (de natureza obrigacional, leia-se) a ser paga para aqueles que dependiam do falecido, a despeito da solidariedade familiar, quantia a ser calculada até a provável expectativa de vida do lesado.

Nos artigos seguintes, 949 e 950, estamos diante da indenização pelos danos provocados à integridade física do lesado que não morreu com o evento danoso, incluída a pensão a ele atribuída em caso de incapacitação para o trabalho. Percebemos a possibilidade da indenização caso haja lesão corporal transcrita na redação dos diplomas acima, sendo que nenhuma referência expressa é feita para o caso de lesões que tenham levado ao dano morte, direcionada ao lesado que pode falecer, a depender do caso, em decorrência dos ferimentos que sofrera.

Com o descrito no artigo 951 do CC, em que as indenizações serão devidas (pela lesão corporal e incapacidade laborativa) mesmo em caso de morte provocada por aquele que, por negligência, imprudência e imperícia, em decorrência de atividade profissional, causar a morte do paciente, agravar-Ihe o mal, causar-Ihe lesão, ou inabilitá-lo para o trabalho. É o caso da responsabilidade médica que hoje encontra mais outras particularidades, como consentimento informado, direito de saber, direito de não saber, além das questões relativas à eutanásia, as quais não dedicaremos maiores atenções.

Em que pese a via ressarcitória prevista no artigo 951, a jurisprudência refere:

Indenização por danos morais. Prescrição não consumada. Autora que se submetera a várias cirurgias para a reparação da queimadura. Relatório médico aponta inclusive retirada de um nódulo em 2010. [...] Requerente que se submetera à cirurgia abdominal, porém, sofrera queimadura de terceiro grau no pescoço. Falha na prestação de serviço médico caracterizada. Inobservância dos cuidados necessários se faz presente. Relação de consumo levada em consideração. Indenização por danos morais está apta a prevalecer. Autora que se submetera a cirurgias reparadoras, logo, além da dor física também fora atingida pela aflição psicológica. Danos morais configurados inclusive 'in re ipsa'. Apelo desprovido. ${ }^{8}$.

Para os profissionais que lidam com a integridade física das pessoas, sobretudo com a atividade médica, o Código Civil brasileiro reserva a preocupação de que danos causados por negligência, imprudência ou imperícia sejam frontalmente combatidos, diante do valor que a vida humana reserva no ordenamento jurídico. Compensam-se os danos provocados reconhecidamente como os danos estéticos, além da prestação alimentar a ser devida pelo

8 Tribunal de Justiça do Estado de São Paulo. $4^{\text {a }}$ Câmara de Direito Privado. APC n. 008073343.2012.8.26.0224. Relator(a): Natan Zelinschi de Arruda. J. em 02/08/2018. Data de publicação: 06/08/2018. In: www.tjsp.jus.br. Acesso em: 08 ago. 2018.

Revista IBERC, Minas Gerais, v. 2, n. 2, p. 01-19, mai.-ago./2019 


\title{
Revista IBERC
}

v. 2, n. 2, p. 01-19, mai.-ago./2019

www.responsabilidadecivil.org

lesante em caso de incapacidade laborativa gerada o lesado. Mais uma vez, pela morte causada com a conduta médica, não há expressa preocupação.

As indenizações arbitradas para os casos de lesão corporal da qual resultem também em danos estéticos, ainda não comportam valores que busquem as razões compensatória e sancionatória da responsabilidade civil, se comparados os valores arbitrados em Portugal ${ }^{9}$, para os mesmos casos:

\begin{abstract}
Apelação cível. Ação de indenização por danos morais e materiais. Autora, menor de idade, vítima de atropelamento, que lhe causou traumatismos e debilidade permanente. Procedência parcial. Condenação ao pagamento de indenização por danos morais no valor de $\mathbf{R} \$ 50.000,00$. Apelo dos promovidos que se limitou ao pleito de minoração do quantum indenizatório. Necessidade de diminuição valor arbitrado, para que fique em sintonia com os precedentes deste órgão julgador. Fixação em $\mathbf{R} \$ \mathbf{3 0 . 0 0 0 , 0 0}$. Provimento parcial do recurso. O valor da indenização por dano moral não deve ser ínfimo a ponto de ferir a dignidade da vítima, nem tão elevado que enseje enriquecimento ilícito da parte. Verificado excesso na quantia arbitrada em primeiro grau, frente aos precedentes desta corte, é imperativa a respectiva minoração ${ }^{10}$. [grifo nosso]
\end{abstract}

Como medida educativa, sancionatória e reparadora, a compensação a ser recebida pelo lesado deve ser adequada à extensão do dano que sofrera, e, de fato, atribuir o valor monetário que corresponda ao dano corporal e/ou moral provocado, convoca a equidade como medida de aplicação da justiça do caso concreto, de relação íntima com a "consciência" do julgador.

Em Portugal, Espanha e Itália, os critérios de valoração da indenização obedecem certos padrões que balizam, mas não determinam, o convencimento do agente decisor. São as Portaria

\footnotetext{
${ }^{9} \mathrm{Cfr}$. julgado que condenara ao pagamento de $12.500 €$ (doze mil e quinhentos euros) pela aflição do lesado com o sofrimento causado pelas dores em seu corpo, resultado de um acidente viário, para além do importe de $50.000 €$ (cinquenta mil euros) pela perda da sua vida. Em reais, o valor total atribuído ao lesado falecido foi de, aproximadamente, $\mathrm{R} \$ 280.000,00$ (duzentos e oitenta mil reais). Disponível em: http://www.dgsi.pt/jstj.nsf/954f0ce6ad9dd8b980256b5f003fa814/6f0296cc8af7f75180257c13005687d4?Open Document\&Highlight=0,dano,da,morte. Acesso em: 08 ago. 2018.

${ }^{10}$ Tribunal de Justiça do Estado da Paraíba. $1^{\text {a }}$ Câmara Especializada Cível. Relator: Desa. Maria de Fátima Moraes Bezerra Cavalcanti. Data de Julgamento: 31/07/2018. Disponível em: http://tjpb-jurisprudenciadje.tjpb.jus.br/dje/2018/8/3/4ae90f57-f0ed-4004-8194-5eac9ae2eaa7.pdf. Acesso em: 09 ago. 2018. In casu, a criança, que à época do acidente contava com 2 meses de vida, sofrera, em decorrência do acidente, fratura do fêmur esquerdo, politraumatismo e traumatismo abdominal fechado, o que resultou em debilidade permanente na função locomoção, pelo encurtamento do membro inferior esquerdo em cerca de $1,5 \mathrm{~cm}$, "o que, além de the trazer abalo moral, fará com que ela experimente uma redução em sua capacidade laborativa, restringindo-lhe o exercício de algumas profissões." O valor arbitrado como compensação pelos danos que sofrera, resumiu-se a $\mathrm{R} \$ 30.000,00$ (trinta mil reais). Em nosso sentir, valor ínfimo, incapaz de compensar o dano causado a uma criança ainda em desenvolvimento, comprometida que resta sua locomoção, para até o fim de sua vida. A sanção, cujo conteúdo tem também caráter de reprovar a conduta dificilmente surtira esses efeitos.
}

Revista IBERC, Minas Gerais, v. 2, n. 2, p. 01-19, mai.-ago./2019 


\title{
Revista IBERC
}

v. 2, n. 2, p. 01-19, mai.-ago./2019

www.responsabilidadecivil.org

de seguros obrigatórios ${ }^{11}$, as baremas espanholas ${ }^{12}$ e a tabela de Milão ${ }^{13}$ que preveem diretrizes na quantificação dos danos corporais, em consideração o fator idade, profissão, v.g., e ao dano morte. Ressalte-se que na Espanha, o dano morte não é indenizável autonomamente, mas há previsão para compensação aos familiares da vítima.

No Brasil, percebemos o ressarcimento por danos morais sofridos pelos sobrevivos, apenas, por direito próprio, arbitrados na margem de $\mathrm{R} \$ 160.000,00$ (cento e sessenta mil reais) pelo STJ, para o caso de perda de filho, da seguinte forma:

\begin{abstract}
AGRAVO REGIMENTAL NO AGRAVO EM RECURSO ESPECIAL. PROCESSUAL CIVIL. NEGATIVA DE PRESTAÇ̃̃O JURISDICIONAL. NÃO OCORRÊNCIA. RESPONSABILIDADE CIVIL. ERRO MÉDICO. PARTO. MORTE DE RECÉM-NASCIDO. REEXAME DO CONJUNTO FÁTICO-PROBATÓRIO DOS AUTOS. SÚMULA No $N^{\circ}$ 7/STJ. AÇÃO DE INDENIZAÇÃO POR DANO MORAL. SUCUMBÊNCIA RECÍPROCA. SÚMULA N $N^{\circ}$ 326/STJ. VALOR ARBITRADO. RAZOABILIDADE. PRECEDENTES DO STJ. 3. O valor fixado a título de indenização por danos morais baseia- se nas peculiaridades da causa. Assim, afastando-se a incidência da Súmula $n^{\circ} 7 / S T J$, somente comporta revisão por este Tribunal quando irrisório ou exorbitante, o que não ocorreu na hipótese dos autos, em que arbitrado em $\mathrm{R} \$ 163.500,00$ (cento e sessenta e três mil e quinhentos reais). Precedentes. 4. Agravo regimental não provido. ${ }^{14}$
\end{abstract}

Retomemos a convocação da equidade ao arbitramento da perda experimentada pelos sobrevivos. Ressaltamos que não há valor monetário hábil a compensar a perda precoce de um ente familiar querido, todavia, compensar monetariamente ainda é a via mais adequada ao suprimento do sofrimento ou sua minoração ${ }^{15}$.

Obedece, portanto, a jurisprudência brasileira, à indenização pelos danos morais sofridos pela perda de um familiar com quem os sobrevivos tivessem vínculo afetivo e familiar. No direito português, esses familiares são, conjuntamente, o cônjuge não separado de pessoas e de bens e aos filhos ou a outros descendentes; na falta destes, aos pais ou outros ascendentes; e, por último, aos irmãos ou sobrinhos que os representem. É possível que seja concedida indenização

\footnotetext{
${ }^{11}$ Portaria de Seguros por acidentes de viação $n^{\circ} 377 / 2008$, alterada pela de $n^{\circ} 679 / 2009$. Na tabela, estão referidos também os danos sofridos pelas lesões físicas e psicológicas antes do falecimento da vítima, considerando-se o período crítico de sobrevivência de até 24 horas da lesão, montante no valor de 2 mil euros; até 72 horas, 4 mil euros e mais que 72 horas, o valor correspondente a 7 mil euros.

${ }^{12}$ Ley $n^{\circ} 30 / 95$ de 8 de novembro.

${ }^{13}$ CEDON, Paolo; NEGRO, Antonello. Danno Biologico e tabelle milanesi. Milano: Giuffrè Editore. 2011. p. XXXII.

${ }^{14}$ Superior Tribunal de Justiça. $3^{\mathrm{a}}$ Turma. AgRg no AREsp 180.480/SP. Rel. Ministro Ricardo Villas Bôas Cueva. Julgado em 18/02/2014, DJe 28/02/2014. In: www.stj.jus.br. Acesso em: 09 ago. 2018.

${ }^{15}$ Neste sentido, Menezes Cordeiro, em texto cuja transcrição elucida: "A questão da imoralidade por percepção de dinheiro, a troco de valores morais pretendidos, tem sido afastada mercê do dinamismo crescente do Direito das obrigações, como disciplina predominantemente patrimonial; os princípios patrimoniais tendem a penetrar em todos os meandros do Direito, até às últimas consequências. Daí que, por abstração, o dinheiro nunca seja imoral; imorais poderão ser certas práticas com ele realizadas, mas isso só releva do foro do beneficiário da indemnização." Cfr. CORDEIRO, António Menezes. Tratado ... p. 515.
} 
Revista IBERC

v. 2 , n. 2 , p. 01-19, mai.-ago./2019

www.responsabilidadecivil.org

ao companheiro e aos filhos ou a outros descendentes, como dispõe o artigo $496^{\circ}, n^{\circ}$ s 2 e 3 . A lei brasileira nada fala a respeito, todavia, diante dos julgados, percebemos a aplicação do mesmo raciocínio do legislador português.

\section{A INDENIZABILIDADE DO DANO MORTE NO BRASIL - UM HORIZONTE PRÓXIMO}

O artigo 948 do Código Civil brasileiro prevê a reparação por danos patrimoniais e extrapatrimoniais quando há morte de alguém decorrente de ato injusto do lesante, conduta devidamente comprovada e o agente identificado, quando, pela letra da norma posta, a indenização consiste no pagamento das despesas com o tratamento da vítima, seu funeral e o luto da família e na prestação de alimentos às pessoas com quem o morto os devia, levando-se em conta a duração provável da vida da vítima, sem excluir outras reparações.

A jurisprudência nos dá testemunhos de que é devida compensação por danos morais, in re ipsa, vale dizer, dispensa a prova da violação da integridade psíquica da pessoa, pela perda de um ente querido ${ }^{16}$.

A claras luzes, percebemos a possibilidade de direcionar a indenização pelo dano morte ao lesado, pois, se a lei expressamente não a proíbe, sua pretensão é possível. Além disto, o caput do artigo 948 determina, para os casos de homicídio, "a indenização consiste, sem excluir outras reparações", o que, diante de uma análise teleológica da norma, poderíamos abrir margem para a previsão do dano morte devido ao de cujus, pela violação da sua vida.

O que a lei e a jurisprudência brasileiras não percebem são fatos particularmente importantes, de ordem da defesa da vida e que obedece ao mandamento constitucional da proteção de sua integridade.

O direito português, pelas breves linhas que the dedicamos, descreve a possibilidade pela reparação por danos causados ao lesado pela perda de sua vida e, ao lado dessa

\footnotetext{
${ }^{16}$ Apelações cíveis. Ação de indenização. Danos morais. Acidente com veículo do município. Vítima fatal. Sucessão relativa. Indenização. Descabimento. Obrigação de indenizar. Danos morais. Razoabilidade e proporcionalidade. Valor majorado. [...]. 1. Não há falar em indenização em virtude de sucessão, quando o pai e companheiro de dois dos autores não faz jus à referida verba, porquanto faleceu em comoriência com a sua genitora, ou seja, não sofreu danos morais em razão do falecimento de sua mãe. 2. Nos termos do art. 37, $\S 6^{\circ}$, da Constituição Federal, o Estado responde objetivamente pelos atos de seus agentes, cabendo-lhe o dever de indenizar os danos deles decorrentes, independentemente da demonstração de culpa/dolo. 3. A majoração da verba para $R \$ 85.000,00$ (oitenta e cinco mil reais), para duas das autoras, a título de indenização por danos morais, mostra-se razoável ante a imensurável dor suportada pela perda da mãe em acidente com veículo do Município, evitando enriquecimento sem causa e respeitando, por outro lado, os princípios da razoabilidade e da proporcionalidade. [...]". Tribunal de Justiça do Estado de Minas Gerais. ${ }^{a}$ Câmara Cível. AC no 1.0134.10.012773-4/001. Relator Des. Armando Freire, J. 03/10/2017. In: www.tjmg.jus.br. Acesso em: 09 ago. 2018.
}

Revista IBERC, Minas Gerais, v. 2, n. 2, p. 01-19, mai.-ago./2019 


\section{Revista IBERC}

v. 2 , n. 2, p. 01-19, mai.-ago./2019

www.responsabilidadecivil.org

perspectiva, dedica preocupação com o ressarcimento por danos corporais, mesmo aqueles decorrentes de ato injusto que levaram o lesado à perda de sua vida.

Trata-se dos momentos de dor pela lesão do corpo, quando, cessados com o decesso, ou não, Ihe é atribuída compensação. Pensemos na realidade de um acidente de viação, do qual decorrera a morte do lesado, mas que antes sofrera com traumatismos que o levaram à morte (danos pré-morte). É neste cenário que a jurisprudência do Supremo Tribunal de Justiça de alémmar nos permite observar outras formas de compensação. Para o caso, a vítima sofrera com as lesões corporais decorrentes do acidente no qual, após o embate, lançada para fora do veículo, verificaram-se traumatismos por todo o corpo. A lesada permanecera sofrendo à beira da estrada, até sua chegada ao hospital, aonde faleceu em decorrência das lesões sofridas. Para tanto, a título de compensação pelos danos corporais que sofrera, até o decesso, fora arbitrada a quantia de 20 mil euros, além de 50 mil euros a título de dano pela perda da vida. Somado a isto, fora concedida às filhas da vítima, por direito próprio, 20 mil euros para uma, com quem a vítima convivia, e 15 mil euros para a outra filha, pelos danos pela perda do seu ente querido ${ }^{17}$, valor aproximado equivalente, hoje, a $\mathrm{R} \$ 315.000,00$ (trezentos e quinze mil reais) à lesada direta e os valores de $R \$ 90.000,00$ (noventa mil reais) e $R \$ 67.500,00$ (Sessenta e sete mil e quinhentos reais) às suas filhas.

Ainda em relação à Portugal, o ressarcimento pelo dano de choque nervoso é devido para aqueles que assistem ao evento e que com o lesado tenha forte vínculo, afetivo ou consanguíneo ${ }^{18}$. Além disto, é possível a compensação por danos causados por morte dos pais ao nascituro ${ }^{19}$, como a via inversa também é observada, vale dizer, o ressarcimento pela perda da vida do nascituro em favor de seus pais, além dos danos corporais porventura sofridos pela mãe.

Ora, retomando o artigo 948 do Código Civil brasileiro, é viável permitir a compensação pelo dano morte, na sua perspectiva mais sancionatória que ressarcitória, por questões óbvias! A seguir a linha de raciocínio do pensamento das legislações portuguesa e italiana ${ }^{20}$, aonde o dano

17 http://www.dgsi.pt/jstj.nsf/954f0ce6ad9dd8b980256b5f003fa814/16c2e8d64e772d358025820900534770?Ope nDocument. Acesso em: 06 ago. 2018).

${ }^{18}$ Cfr. Código Civil português, Artigo 496" "Danos não patrimoniais [...] 4. [...] no caso de morte, podem ser atendidos não só os danos não patrimoniais sofridos pela vítima, como os sofridos pelas pessoas com direito à indemnização nos termos dos números anteriores."

19 Disponível em: http://www.dgsi.pt/jstj.nsf/954f0ce6ad9dd8b980256b5f003fa814/28aff17cdabb90e880257cb00034dcc2?Open Document\&Highlight=0,dano,da,morte. Acesso em: 06.Ago.2018.

${ }^{20}$ Art. 2043 "Risarcimento per fatto illecito - Qualunque fatto doloso o colposo, che cagiona ad altri un danno ingiusto, obbliga colui che ha commesso il fatto a risarcire il danno (Cod. Pen. 185)." Disponível em: http://www.jus.unitn.it/cardozo/obiter_dictum/codciv/Lib4.htm. Acesso em: 07 Ago 2018. Cfr. "La privazione del bene-vita - si releva intal senso- costituisce un'alterazione irremediable dello stato di salute di um individuo, tale da cauargli un «danno biológico dela massima entità». BARZAZI, Guido; BOSIO, Paola; DEMORI, Angelo; RONCALI, Davide. II Danno Da Morte biologico e morale. Padova: Cedam, 2000. p. 25.

Revista IBERC, Minas Gerais, v. 2, n. 2, p. 01-19, mai.-ago./2019 


\section{Revista IBERC}

v. 2 , n. 2 , p. 01-19, mai.-ago./2019

www.responsabilidadecivil.org

morte é indenizável por via autônoma, perquirimos o necessário alargamento da Responsabilidade civil brasileira a esta espécie de dano.

Ao tratarmos dos pressupostos da responsabilidade civil convocados para 0 ressarcimento de danos, constatamos o ato ilícito, violar os direitos de alguém que consistem, no caso, em abreviar a vida da pessoa, violação de um direto absoluto, consistente na afronta a um direito imaterial, transgredido o dever de cuidado, neminem laedere.

A análise da imputabilidade traduz a consciência do lesante na sua atitude lesiva, o caráter ilícito do seu ato e a capacidade de dirigir seu comportamento de acordo com sua vontade. É a culpa, e dessa forma age quem deveria e poderia ter evitado a conduta lesiva. Traduz-se, também a imputação na análise da intenção, o dolo, é dizer que o agente quis o resultado danoso e lesivo, ilícito, portanto.

Outras nuances do dolo, a exemplo do dolo necessário, aceitar o resultado, embora necessário para a almejar o objetivo da sua conduta, enquanto o dolo eventual reside na não intenção do resultado, embora assuma-se o risco da sua produção, e o aceite, de forma eventual. Há, no dolo, portanto, o conhecimento, por parte do agente, das circunstâncias, assunção de uma esfera de risco que está no contorno da sua conduta ilícita.

Quer isto dizer que, alguém que viola normas de trânsito, por exemplo, a exceder a velocidade da via, e vem a causar acidente com vítima fatal, é responsável pelo resultado que provocou e por isto deve responder, uma vez que a finalidade da norma - velocidade máxima permitida - é a de evitar acidentes de tráfego. Vale dizer, o agente assumiu o risco de produzir o resultado - acidente com vítima fatal.

Já a conduta ilícita não intencional, está diretamente ligada a uma omissão atrelada à falta de cuidado - a negligência, ou a uma conduta comissiva, para o caso da imperícia. $\mathrm{Na}$ análise da culpa, põe-se em causa a comparação à situação que seria tomada por um homem médio, que agiria com diligência na mesma situação, medianamente responsável por atuar de forma diversa, caso exigível.

É, nas palavras de Sinde Monteiro ${ }^{21}$, considerar que a vida em sociedade exige que possamos contar com o mínimo de qualidades positivas nos outros, postulada no princípio da confiança na atuação dos outros, gravemente afetada quando admitidas isenções de culpa puramente individuais. Continua o autor a descrever que a conduta de cada um deve ser adaptada ao comportamento e ao que é normalmente exigível no tráfico.

Como fundamento relevante da Responsabilidade civil, o dever de abster-se de ofender outrem, quando desrespeitado, a ponto de provocar o dano em alguém, é que se constitui a

${ }^{21}$ MONTEIRO, Jorge Ferreira Sinde. Rudimentos da Responsabilidade Civil. In: revista da Faculdade de Direito da Universidade do Porto. Coimbra: Coimbra editora, 2005. p. 373. 


\section{Revista IBERC}

v. 2 , n. 2, p. 01-19, mai.-ago./2019

www.responsabilidadecivil.org

finalidade precípua da reparação dos danos. Nasce, portanto, a relação jurídica e, quando o dano provocado é a abreviação da vida de uma pessoa, providências precisam ser tomadas pelo Estado enquanto agente de pacificação social, sobretudo violado o maior valor moral e jurídico conhecido, a vida humana.

Há flagrante lesão ao bem juridicamente protegido, a vida, não avaliável pecuniariamente, cujos prejuízos não incomensuráveis, além do que qualquer outra lesão à vida como à integridade psicofísica, é ressarcível civilmente, o que não é absurdo se falar em indenização pela perda do direito de viver.

Bem assim entendido, outros danos que se referem à vida também estão em causa e sua consequente compensação, vale dizer, dano da vida (Wrongful actions) ${ }^{22}$, danos por violência obstétrica $^{23}$, a exemplo de outras situações particulares.

Imperioso referir que a existência da relação de causa e efeito entre a conduta do lesante e o resultado, no caso, morte do lesado, é fator hábil para completar os elementos de condição para a convocação da Responsabilidade civil e aplicabilidade de suas funções. A causa do dano morte deve ser aquela determinante para a provocação do resultado lesivo, afastadas as causas remotas ou meramente especulativas. Trata-se, da causa necessária, conditio sine qua non, cujo decorrer dos fatos converge no evento lesivo, a causa adequada apta a produzir o resultado morte, $v . g$, ultrapassar a velocidade permitida na via e atingir uma pessoa que atravessa o logradouro na faixa exclusiva para pedestres, verificada que se a velocidade estivesse sendo obedecida, o evento morte não teria ocorrido. É, portanto, a causa apropriada para produzir o dano morte.

Depois, refira-se as funções da responsabilidade civil pautadas na reação ao fato ilícito danoso, com função de reparação, quer isto dizer, repristinação do lesado ao status quo ante; reafirmação do poder repressor do Estado, além da função de desestímulo da conduta ${ }^{24}$, de caráter sancionatório. Dito isto, questionamentos acerca da impossibilidade prática da compensação pelo dano morte poderiam surgir e encaminhar nosso pensamento conclusivo ao seguinte inconveniente: como se daria retorno do lesado ao status quo ante?

\footnotetext{
${ }^{22}$ Cfr. Caso Perruche, julgado em $200^{\circ}$, sob o Acórdão de $n^{\circ} 457$, Corte de Cassação francesa. Disponível em:

https://www.courdecassation.fr/jurisprudence_publications_documentation_2/bulletin_information_cour_cassa tion_27/bulletins_information_2000_1245/no_526_1362/. Acesso em: 06.Ago.2018.

${ }^{23}$ Tribunal de Justiça do Estado de São Paulo. $1^{\text {a }}$ Vara Cível. Processo n. 1003315-16.2015.8.26.0609. Disponível em: https://esaj.tjsp.jus.br/cjsg/getArquivo.do?conversationld=\&cdAcordao=10877095\&cdForo=0\&uuidCaptcha $=\$$ ajcaptcha_88b1f5c711d3433284c00bf7da4e132c\&vICaptcha=eUM\&novoVICaptcha=. Acesso em: 06 ago. 2018.

${ }^{24}$ ROSENVALD, Nelson. As funções da responsabilidade civil. $2^{a}$ ed. São Paulo: Atlas, 2014. p. 16.
}

Revista IBERC, Minas Gerais, v. 2, n. 2, p. 01-19, mai.-ago./2019 


\section{Revista IBERC}

v. 2, n. 2, p. 01-19, mai.-ago./2019

www.responsabilidadecivil.org

Para o dano morte, não se trata disto, definitivamente. É um prejuízo de proporções desmedidas, que leva ao fim da vida de alguém, ciclo vital abreviado por ato injusto.

Uma vez consumado o decesso como resultado de um fato lesivo imputado a alguém, a atribuição da indenização ao de cujus se dá a respeitar a função sancionatória da conduta. Assim como lesões corporais são indenizáveis, a exemplo do dano estético no Brasil ${ }^{25}$, não indenizar o lesado que sofrera fisicamente a ponto de ter sua vida abreviada é não abarcar o dano biológico de máxima extensão, lesão incomensurável à saúde ${ }^{26}$, uma vez que é a morte a perda absoluta e irreversível da integridade psicofísica.

A compensação pelo dano morte reside exatamente no sentido e alcance que hoje a responsabilidade civil comporta, um papel denso e complexo. Visa reparar um dano sofrido, excluída a responsabilização baseada na culpa somente, mas pelos atos praticados também como medida sancionatória e punitiva ${ }^{27}$.

Pensemos pela via de que a vida é um interesse protegido por lei, o que é incontroverso. Antes, é válido considerar que deve existir o respeito à pessoa, ser existente, "dada a experiência mais imediata do olhar e do sentido, vale dizer, é a primeira lei do justo, o primeiro dever indissociavelmente moral e jurídico que se impõe ${ }^{28}$."

Mesmo com o evento morte, a cessar a personalidade jurídica do lesado que falece, pensamos ser mesmo este evento o constituidor do direito na esfera jurídica do de cujus, uma vez que o evento morte que é um fato constitutivo de várias relações jurídicas outras, a exemplo do pagamento de seguro de vida, ou modificativo, quando percebemos a transmissão das obrigações aos herdeiros do falecido, além de resguardada para após a morte a personalidade jurídica das

${ }^{25}$ Cfr. o seguinte julgado: INDENIZAÇÃO POR DANOS MORAIS, MATERIAIS E ESTÉTICOS. ACIDENTE DE TRÂNSITO. TRANSPORTE COLETIVO. CONDENAÇÃO SOLIDÁRIA AO PAGAMENTO DE INDENIZAÇÃO POR DANOS MORAIS E MATERIAIS. SENTENÇA PELA PROCEDÊNCIA PARCIAL DO PEDIDO. [...]. RESPONSABILIZAÇÃO EXCLUSIVA DA EMPRESA QUE DEU CAUSA AO ACIDENTE. RECURSO PROVIDO., Tribunal de Justiça do Estado da Paraíba. $4^{a}$ Câmara Especializada Cível. Processo $\mathrm{n}^{\circ}$ : 07593132420078152001. Relator: Des. Romero Marcelo da Fonseca Oliveira. Data de Julgamento: 26-062018. Disponível

em: http://juris.tjpb.jus.br/search?q=dano+est\%C3\%A9tico\&as_oq=\&as_eq=\&as_epq=\&site=jurisp_di gitalizada\&decisao=todos\&client=tjpb_index\&output=xml_no_dtd\&proxystylesheet=tjpb_index\& oe $=$ UTF-8\&ie=UTF-

$8 \&$ ud $=1 \&$ filter=0\&Ir=lang_pt\&getfields $=* \&$ sort=date\%3AD\%3AS\%3Ad1\&requiredfields=BASE\%3A Acordaos\%7CBASE\%3ADecisao\&as_q=. Acesso em: 07 ago. 2018.

${ }^{26}$ Cfr. BARZAZI, Guido; BOSIO, Paola; DEMORI, Angelo; RONCALI, Davide. II Danno Da Morte biologico e morale. Padova: Cedam, 2000. p. 25.

${ }^{27}$ LUCAS, Francisco Manuel. Uma outra visão. Coimbra, 2013. p. 101.

${ }^{28}$ NEVES, António Castanheira. Pessoa, direito e responsabilidade. In: Revista Portuguesa de Ciência Criminal. Ano 6. Jan-Mar 1996, Coimbra: Coimbra Editora. p. 35. Continua o autor a afirmar que enquanto se confere dignidade à pessoa, "o homem não só ascende, enquanto pessoa, à axiologia e se faz participante e sujeito do reino dos fins, do mundo dos valores, como tem sentido e fundamento já o comprometer-se (ético) perante os outros", isto o torna responsável, "pode e deve re-spondere". NEVES, António Castanheira. Pessoa.... p. 36.

Revista IBERC, Minas Gerais, v. 2, n. 2, p. 01-19, mai.-ago./2019 


\section{Revista IBERC}

v. 2, n. 2, p. 01-19, mai.-ago./2019

www.responsabilidadecivil.org

pessoas já falecidas. Isto em atendimento, de início, ao resguardo do direito à vida em atenção à sua dignidade, de onde decorrem os direitos de personalidade.

Refira-se a percepção de que contatos sociais ensejam a responsabilização por danos. Retomando as lições de Sinde Monteiro, "o dano fica com quem o sofre",29, o que conduz nosso pensamento conclusivo, caso desconsiderada a compensação pelo dano morte como categoria autonomamente indenizável, a acreditar que seria preferível, neste estado das coisas, matar do que ferir.

Postas estas razões, dirigimos na via da possiblidade de convocação da responsabilidade civil em atenção ao dano morte. Trata-se de uma lesão máxima sofrida por alguém que teve sua vida abreviada por ato injusto provocado pelo lesante, desrespeitada que restou a integridade psicofísica do lesado que falece, mais ainda, estamos diante de ofensa ao estatuto ético moral e jurídico, que é o dever da preservação da vida humana, nas suas mais completas faces.

\section{CONCLUSÃO}

Em que pese a defesa da vida como valor absoluto, intrínseco à própria finalidade do Direito, sua preservação é ação impreterível aos Entes públicos. Ressalvam-se outras questões, como as relativas ao aborto, eutanásia, por tratarem-se de aspectos em que o fim da vida deve ser determinado, por razões outras.

Aqui, abordamos a defesa da vida e ressarcimento pelo dano morte provocado por ato injusto. Embora de conhecimento inequívoco de que o fim da vida é o caminho ao qual percorreremos naturalmente, não se ousa pensar que a violação deste bem jurídico seja isento de responsabilização por aquele que abrevia a existência de uma pessoa, sem qualquer razão de ser, e nem haveria razões para se acreditar nesta hipótese!

Ao percorrer a defesa da vida nas Constituições democráticas, percebemos a preocupação da ação do Estado em promover a proteção da vida humana, em amplos aspectos, e a inação do Poder Público em não ofender os direitos reconhecidos do ser pessoa. Portanto, falar em convocar a Responsabilidade civil para ressarcir àquele que teve seu ciclo vital furtivamente diminuído, não é absurdo, nem inconstitucional.

Ao contrário, tratamos da vida como direito de personalidade, do qual decorrem todas as outras perspectivas dos direitos da pessoa, resguardado nos Códigos Civis de países, que

${ }^{29}$ MONTEIRO, Jorge Ferreira Sinde. Rudimentos da Responsabilidade Civil. In: revista da Faculdade de Direito da Universidade do Porto. Coimbra: Coimbra Editora, 2005. p. 353.

Revista IBERC, Minas Gerais, v. 2, n. 2, p. 01-19, mai.-ago./2019 


\section{Revista IBERC}

v. 2 , n. 2 , p. 01-19, mai.-ago./2019

www.responsabilidadecivil.org

inclusive preveem a ressarcibilidade do dano morte devida ao de cujus, mesmo pelo fim de sua vida, a exemplo dos ordenamentos português e italiano.

No diploma cível brasileiro, expressamente, não se percebe, a uma primeira leitura, a possibilidade de compensação pelo decesso de uma pessoa que sofre com uma conduta, omissiva, ou comissiva, a ponto de perder sua vida. Bem assim, pela compreensão atenta do caput artigo 948, de onde se extrai, expressamente, "sem excluir outras reparações", a abertura à indenizabilidade do dano morte como dano autônomo devido ao de cujus, pelo seu falecimento, como um direito próprio, sem excluir a já prevista possibilidade de compensação por danos morais in re ipsa aos familiares do lesado falecido.

Da jurisprudência referida, comparadas à jurisprudência portuguesa, ainda percebemos compensações tímidas, não razoáveis, pequenas, insignificantes, a ponto de fazer o lesado suportar as dores físicas, muitas das quais serão sentidas pelo resto da vida, para além da reparação pela dor da saudade experimentada pelos que sofreram perda irreparável, para os casos de lesão corporal máxima, hábil a levar o lesado à morte.

Nosso pensamento conclusivo nos dirige, por fim, em, uma vez que se reconhece a vida como valor supremo a ser protegido pelo Estado, inimaginável pensar na não compensação pelo dano morte como dano autônomo a ser inserida na esfera jurídica do lesado mesmo com o evento morte, fato gerador de tantas outras relações jurídicas.

Depois, pensar no quantum indenizatório pela perda da vida é fator relevante a ser considerado, sobretudo no Brasil, onde indenizações, mesmo pelos danos corporais são concedidas, muitas vezes, em valor ínfimo, incapaz de ressarcir ao dano provocado, menos ainda, a atender as funções para as quais a Responsabilidade Civil é convocada. Pensaremos neste pormenor em outra oportunidade.

\section{REFERÊNCIAS}

BARBOSA. Mafalda Miranda, (Im)pertinência da autonomização dos danos puramente morais? Considerações a propósito dos danos morais reflexos. In: Cadernos de direito privado. Jan-Mar 2014, n 45 , p. 3-18.

BARZAZI, Guido; BOSIO, Paola; DEMORI, Angelo; RONCALI, Davide. II Danno Da Morte biologico e morale. Padova: Cedam, 2000.

BOBBIO, Norberto. Locke e o direito natural. Brasília: Editora UNB, 1997.

BRASIL. Superior Tribunal de Justiça. AgRg no AREsp 180.480/SP. Rel. Ministro Ricardo Villas Bôas Cueva, terceira turma, julgado em 18/02/2014, DJe 28/02/2014. 


\section{Revista IBERC}

v. 2 , n. 2 , p. 01-19, mai.-ago./2019

www.responsabilidadecivil.org

CAMPOS, Diogo Leite de. OS danos causados pela morte e sua indenização. In: Comemorações dos 35 anos do Código Civil e dos 25 anos da Reforma de 1977. Vol III, Das Obrigações. Coimbra: Coimbra editora, 2007.

CORDEIRO, António Menezes. Tratado de Direito Civil português - Vol. II Direito das obrigações T. III Gestão de negócios, Enriquecimento sem causa; Responsabilidade civil. Coimbra: Almedina, 2010.

CORTE-REAL, Carlos Pamplona. Curso de Direito das Sucessões. Lisboa: Quid Juris, 2012.

DIAS, João António Álvaro. no direito do ser humano de não ser morto. In: Dano corporal quadro epistemológico e aspectos ressarcitórios. Coimbra: Almedina, 2004.

FERRO, Ana Luiza Almeida. O Tribunal de Nuremberg: dos precedentes à confirmação de seus princípios. Belo Horizonte: Mandamentos, 2002.

FRADA, Manuel A. Carneiro da. Nos 40 anos do Código Civil Português Tutela da Personalidade e dano Existencial. In: Themis Revista de Direito, Edição Especial. Ano: 2008.

LUCAS, Francisco Manuel. Uma outra visão. Coimbra, 2013.

MINAS GERAIS. Tribunal de Justiça do Estado. $A C n^{\circ}$ 1.0134.10.012773-4/001, Relator: Armando Freire, $1^{\text {a }}$ CÂMARA CíVEL, J. 03/10/2017). Disponível em: http://www.dgsi.pt/jstj.nsf/954f0ce6ad9dd8b980256b5f003fa814/16c2e8d64e772d358025820900534770? OpenDocument. Acesso em: 06 ago. 2018

MONTEIRO, Jorge Ferreira Sinde. Rudimentos da Responsabilidade Civil. In: revista da Faculdade de Direito da Universidade do Porto. Coimbra: Coimbra editora, 2005.

NEVES, António Castanheira. Pessoa, direito e responsabilidade. In: Revista Portuguesa de Ciência Criminal. Ano 6. Jan-Mar 1996, Coimbra: Coimbra Editora, 1996.

ROSENVALD, Nelson. As funções da responsabilidade civil. $2^{\mathrm{a}}$ ed. São Paulo: Atlas, 2014.

TELES. Inocêncio Galvão, Direito das Sucessões. Noções fundamentais. $6^{a}$ ed. Coimbra: Coimbra Editora, 1996.

SÃO PAULO. Tribunal de Justiça do Estado. Processo $n^{o}$ : 1003315-16.2015.8.26.0609. Disponivel

em:

https://esaj.tjsp.jus.br/cjsg/getArquivo.do?conversationld=\&cdAcordao=10877095\&cdForo=0\&uuid Captcha=sajcaptcha_88b1f5c711d3433284c00bf7da4e132c\&vICaptcha=eUM\&novoVICaptcha=. Acesso em: 06 ago. 2018.

PARAíBA. Tribunal de Justiça do Estado. $1^{a}$ Câmara Especializada Cível. Relator: Desa. Maria De Fátima Moraes Bezerra Cavalcanti. Data de Julgamento: 31-07-2018 Disponível em: http://tjpb-jurisprudenciadje.tjpb.jus.br/dje/2018/8/3/4ae90f57-f0ed-4004-8194-5eac9ae2eaa7.pdf. Acesso em: 09 ago. 2018.

PARAÍBA, Tribunal de Justiça do Estado. Processo $n^{\circ}$ : 07593132420078152001 . Relator: Des. Romero Marcelo da Fonseca Oliveira. Órgão Julgador: $4^{a}$ Câmara Especializada Cível. Data de Julgamento: 26-06-2018. Disponível

em: http://juris.tjpb.jus.br/search?q=dano+est\%C3\%A9tico\&as_oq=\&as_eq=\&as_epq=\&site=jurisp_digi talizada\&decisao=todos\&client=tjpb_index\&output=xml_no_dtd\&proxystylesheet=tjpb_index\&oe=U 


\section{Revista IBERC}

v. 2, n. 2, p. 01-19, mai.-ago./2019

www.responsabilidadecivil.org

TF-8\&ie=UTF-

$8 \&$ ud $=1 \&$ filter $=0 \& \mid r=$ lang_pt\&getfields $=*$ \&sort $=$ date $\% 3 A D \% 3 A S \% 3 A d 1 \&$ requiredfields $=B A S E \% 3 \mathrm{~A}$ Acordaos\%7CBASE\%3ADecisao\&as_q=. Acesso em: 07 ago. 2018.

VARELA, Antunes. Das obrigações em geral. Vol. I, 10 ed. Rev. e Atual. Coimbra: Almedina, 2014.

VASCONCELOS, Pedro Pais. Direito de personalidade. Coimbra: Almedina, 2014.

Recebido: 09.08.2018

Aprovado: 24.02 .2019

Como citar: CAVALCANTI, Camila de Araújo. Indenizabilidade do dano morte no Brasil. Revista IBERC, Minas Gerais, v. 2, n. 2, p. 1-19, mai.-ago./2019. 